Short Communication

\title{
Hydrothermal Synthesis of $\mathrm{MnO}_{2}$ with Different Morphological Characteristics as Electrode Material for High Electrochemical Performance Supercapacitors
}

\author{
Ying Zheng ${ }^{1, *}$, Xianfeng Zheng ${ }^{2}$ \\ ${ }^{1}$ School of Vehicle Engineering, Xi'an Aeronautical University, Xi'an, 710165, China. \\ ${ }^{2}$ Measuring and Testing Institute Under Xi'an Aerospace Corporation, Xi'an, 710100, China. \\ "E-mail: profzhengying@aliyun.com
}

doi: $10.20964 / 2020.02 .57$

Received: 2 October 2019 / Accepted: 10 December 2019 / Published: 31 December 2019

The morphology of the materials has a direct influence on the electrochemical performance of the electrode materials for the supercapacitors. Many works have been reported the improvement of electrochemical performance by designing different kinds of electrode materials for supercapacitors. However, the researchers have paid little attention about the influence of nanostructures of one material on the supercapacitors. Therefore, we developed morphology controlled $\mathrm{MnO}_{2}$ nanostructures, including $\mathrm{MnO}_{2}$ nanospheres (MN-NS) and $\mathrm{MnO}_{2}$ nanocages (MN-NC), to modify the electrochemical performance of the supercapacitors. The electrochemical performance indicates that the as-prepared MN-NC electrodes exhibit higher specific capacity and superior cycle stability. This is ascribed to the hollow nanocages of MN-NC providing enough electrolyte to ensure the wettability of the whole electrode film.

Keywords: Supercapacitor, $\mathrm{MnO}_{2}$, nanocages, nanostructures, Capacity, Energy density, New energy

\section{FULL TEXT}

(C) 2020 The Authors. Published by ESG (www.electrochemsci.org). This article is an open access article distributed under the terms and conditions of the Creative Commons Attribution license (http://creativecommons.org/licenses/by/4.0/). 